\title{
浅谈海外工程物资采购与管理的认识和体会
}

\author{
王玲 \\ 国家电投集团远达环保工程有限公司 \\ DOI:10.32629/ej.v2i3.165
}

[摘 要] 随着 “中国工程” 走出国门,特别是在“一带一路”的战略引领下,中国电力环保已参与到越来越多发展中国家的基 础设施建设之中, 这在给电建业创造众多机遇的同时也提出了挑战。俗话说: 军马未动, 粮草先行。物资之于工程好比军需之 于战役, 在国际工程中如何科学合理规划采购、调配物资, 确保工期进度,同时降低消耗、节约成本, 提高企业经济效益,发挥着 举足轻重的作用。笔者切合自身多年实践的海外工程物资采购与管理体会,与各位读者分享,不足之处,望予指正。

[关键词] 国际工程; 物资采购与管理; 成本控制

根据物资采购和物流的时间维度, 大致归纳为三个阶 段: 采购和合同谈判, 监造、物流集港和清关, 货到现场管理。 不同阶段物资管理有不同的侧重点, 在下文中一一详述。

\section{1 采购和合同谈判阶段}

由于物资设备供应与海外工程项目进度直接相关, 物资 采购计划的编制、合同内容的策划密切关系后续物流链执行 效果的好坏, 必须从预见性、专业性、准确性和三个方面提 前着手。首先, 海外现场踏勘之初, 物资人员应提前介入, 预 先了解项目所在国当地物资的供货能力、价格水平、物流情 况, 作为物资采购计划编制的重要依据。其次, 要根据总包收 汇方式的不同, 即, “直接出海-外汇结算型”、“搭船出海人民币结算型”, 采取不同的付汇和物流模式, 以实现利润和 资金利用的最大化。在 “直接出海-外币结算型” 项目中, 除了在总包合同中充分考虑结汇风险, 必要时可采取信用保 险、银行方案降低风险外, 还应对出口清关的各类物资报关 要素进行全面和准确的分析, 作出稳妥且适时的海关 HS 编 码预归类及退税方案策划。基于上述退税策划, 做出适配的 工程物资标段划分和采购计划编制, 启动物资招标采购。在 招标过程中, 根据设备和材料专有性及技术难度的高低, 进 行国内采购、属地采购、第三国采购三维度的价格比较, 选 取同时满足技术和工期要求, 且成本最优的付汇模式。对于 一些技术含量较高、专业性较强、供货商有限的设备, 若采 用先入关 (中国), 再出口 (项目国) 的方式, 其物流成本和耗 时远高于从第三国直接发往项目所在国, 鉴于此, 建议直接 与供货商进行外币结算, 货物由第三国直达项目属地方式签 订合同。但此种情况需注意外汇核销的相关手续和文件的准 备。在 “搭船出海-人民币结算型” 项目中, 二包方应多争取 国内总包方的外汇资金流, 以解决中国境外物资供货的货款 支付。通过总包方先垫付 (外汇)、后结算 (人民币) 的模式, 一来避免汇率风险造成的物资采购成本失控, 再者减少了项 目现金流的占用, 从而达到经营成本最低和资金利用最大的 效果。

在与供货商分包合同谈判中, 还需注意以下几个方面: (1) 在设备质量保证期、最终验收时间上尽量与总包合同保
持一致, 避免因总分包时间差导致的总包履约成本增加; (2) 物资价格组成不仅只限于设备费和国内税费、运保费, 还应 覆盖从设计到制作完成、配合监造、工厂性能试验、出口包 装、出口商检、出口熏蒸、海外标准认证配合、现场技术服 务、整套系统的性能保证和售后服务等一系列综合费用。对 于现场技术服务时间不确定的情况, 行之有效的办法是约定 标准人日价和差旅费, 最终费用按照现场项目经理签发进行 结算。若不在合同中提前约定, 工程后期存在供货商派员服 务坐地起价的风险。（3）合同的付款条款应与供货商提交外 贸单证、质量文件、技术文件严格挂钩。“重交货、轻单证” 一直是物资出口中的顽疾, 在发货/到货款中加强对单证完 整性提交的约束, 是保证物资与文件 “交货” 的同步完成的 最好措施。(4) 分包合同中对出口包装要求和监造标准, 应不 低于总包相关约定。对于不同的项目所在国属地专有的技 术、质量、准入标准, 应在合同签订时纳入到监造 ITP 条款 中进行过程控制。

\section{2 监造、物流集港和清关阶段}

物资在合同签订后进入生产制作阶段。对于工程节点和 质量有重大影响的物资、材料, 应该在排产过程中进行全方 位的工艺流程、进度、质量、(国际) 标准监造控制。控制措 施可采取定期电话跟踪设备进度、定期通过制造商提交相关 文件资料(如设备制造过程的一些照片、一些试验检验报告 等) 跟踪、或者按照《设备监造检验计划表 ITP》的计划安 排派遣监造人员到制造商巡检、驻厂监造设备进度等方式进 行。监造见证、检查的形式有 H、W、R、I 四种, 具体含义如 下: $H$ 点: 停工待检。制造商在进行至该点时必须停工等待 监造工程师参加的检验或试验项目, 并进行停工待检见证。 未经监造工程师到现场见证或者没有经过监造工程师书面 同意, 制造商不能进行下步工作; $W$ 点: 现场见证点。如监 造工程师不能按时到达见证现场, 制造商可以进行下一步工 作; $\mathrm{R}$ 点: 文件见证, 由监造工程师依据相关标准及要求, 检 查设备制造过程中形成的各种文件资料, 包括检查其完整 性、真实性等; I 点: 监造工程师在制造商内进行的复查、 抽检、试验及金属焊接的无损探伤等。特别注意的是, 那些 
必须在制造工厂预组装、试验的设备, 制造过程达到相应节 点, 则必须按照合同监造 ITP 要求进行设备检验和试验。对 符合检验要求的, 进入下一个生产环节; 不符合的, 由总包方 开立 “不符合项” 报告, 制造商提出整改解决措施, 直至符合 检验要求。不符合项的管理流程分为: 识别、处置、关闭及 纠正措施四个步骤。监造人员对不符合项的报告的异常或可 疑情况, 应立即进行查证、鉴别, 确认是否属于不符合项。处 置方法包括: 返工、返修、降级使用、原样接收或补充措施、 报废/拒收。处置后未经过规定认可和重新检验合格的不得 转入下道工序或交付。对未按期关闭的不符合项和事件, 责 任单位应及时分析原因并采取有效措施, 还应及时报告监造 人员, 避免因关闭不及时而造成事故。物资监造不合格项经 总包方分级验证合格后, 方予关闭, 质量放行。

通过质量放行后, 设备进入数量核对和包装核对检查阶 段。专业技术人员要严格按照设计图纸核对设备材料实际发 运规格、数量, 确保物资实际供货与设计一致(钢结构、管件 材料由应如此)。此外, 出口包装方案和运输方案应完全响应 总包合同约定, 满足国内大部件运输及集港的相关要求。装 箱过程中, 对货物拍照存档, 以备现场开箱后对外包装、内包 装箱单核对。

出口包装熏蒸。若包装材料中含有实木材质, 应在制造 商属地完成实木包装熏蒸工作, 并取得相应 IPPC 熏蒸检验 合格证, 箱外表面打印 IPPC 标识, 便于出口检验检疫, 熏蒸 检验合格证也应注意效期有效至货物出口清关离港完毕。根 据国家商检法必须进行法定商检的物资, 制造商应在属地申 报商检，商检单位的填报，应得到总包商或 EPC 方确认同意。

完成上述工作后, 制造商按照总包商要求时间、地点按 期集港、取得码头签收单, 进入出口清关环节。物资采购方 应对货物外包装拍照留档进行二次验收, 若出现箱件严重破 损、单货不一致, IPPC 熏蒸标识不清、熏蒸证明效期不符、 法检未检等情况, 应拒绝接货、立即整改, 直至合格。对于“直 接出海-外汇结算型” 总包模式, 要特别注意出口申报要素与 退税的细节, 核对制造商提供的增值税票品名、数量、规格 是否一致, 避免退税不良的风险。

\section{3 货到现场管理阶段}

货物历经国际运输后, 抵达项目所在国港口。根据总包 外贸术语界定, 总包方负责/配合进口方完成清关工作, 并做 好货证不符、箱件破损、丢失等相关记录; 到达施工现场后,
业主、现场物资人员、制造商代表三方同时见证开箱检验并 做好细节记录, 签字存档。对于无法按期抵达现场进行开箱 验收的合同方, 应提前提供《委托现场开箱验收函》, 以解决 现场差缺件的补供问题。工程物资到达现场后, 应及时完成 验收、开箱、结算等各项工作, 促成材料进度良性循环, 便于 资金周转。

海外现场的物资管理工作, 专业人员首先要根据物资设 备数量、性能、类别等进行合理规划并参考工期使用进度, 制定不同的存储、维保方案和仓库安排, 提高库存能力, 全面 做好到货前准备。其次, 建立物资设备信息档案, 建立物资专 门数据库, 记录物资到货计划、实际到货、规格、数量、保 养与维修信息, 备件和专用工具信息、使用寿命、适用范围 等信息, 量化各类物资、设备的追加库存数量与周期, 以便提 前做出需求计划, 做到灵活的调节与补充, 满足工程进度的 推进。

海外工程的现场物资管理还应注意文件的移交(整理、 翻译) 同物资移交等同重要。文件类型包括：技术文件、蓝 图材料清单、设计院图纸编号说明、箱件清单、装箱清单、 设备清册、设备使用说明书、设备合格证、设备质保证明等。

现场物资人员在接收货物同时, 主动有意识地将上述文 件资料收纳整理建册, 发现差缺, 立即提出要求制造商限期 补交, 否则等到项目移交时备齐, 难度大幅增加, 耗时耗钱。

综上所述, 海外工程的物资管理是一项专业性强、综合 性高的系统工作。要求相应的物资管理人员具备较高的物 资、外贸、物流专业素质。随之配套的物资管理制度也应紧 密联系海外工程实际发展需要, 从源头上规范物资采购、监 造、物流、库存和使用等环节的各项工作, 使物资、资金、单 证按照预定轨道进入执行层面, 保证工程的质量和进度, 控制 经营成本, 按期回笼资金, 实现国有品牌效益和经济效益的最 大化。

\section{[参考文献]}

[1]王相,孙跃众.浅谈海外工程项目设备采购与使用管 理[J].建设机械技术与管理,2009,(10):40-43.

[2]苏志娟, 陈辉.浅谈加强国际管道工程物资采购管理 降低采购成本的几点认识[J].纳税,2000,(09):12.

[3]佚名.加强物资采购管理降低综合采购成本[J].企业 技术开发(学术版),2009,(10):125-135. 